UCRL-ID-118418

\title{
Monitoring Six-Phase Ohmic Heating of Contaminated Soils Using Electrical Resistance Tomography
}

RECEIVED

APR $05\{996$

A. L. Ramirez

OSTI

W. D. Daily

September 1994

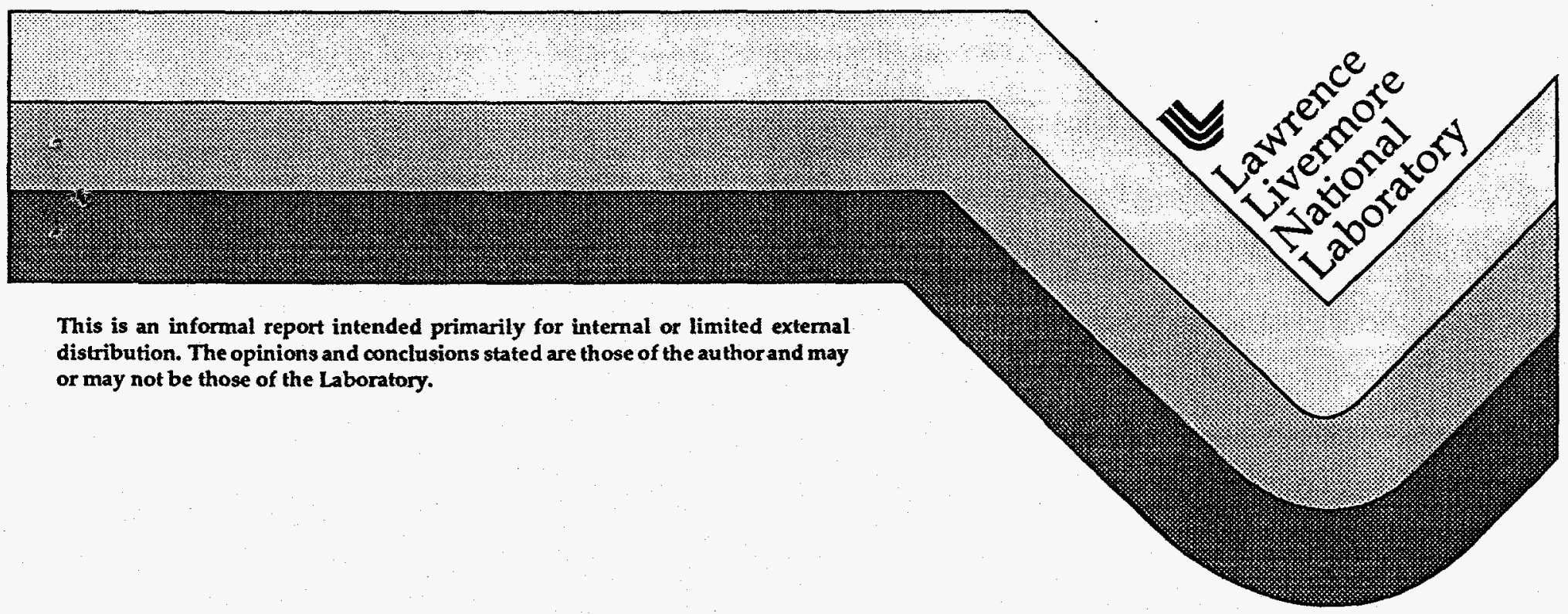




\section{DISCLAIMER}

This document was prepared as an account of work sponsored by an agency of the United States Government. Neither the United States Government nor the University of California nor any of their employees, makes any warranty, express or implied, or assumes any legal liability or responsibility for the accuracy, completeness, or usefulness of any information, apparatus, product, or process disclosed, or represents that its use would not infringe privately owned rights. Reference herein to any specific commercial products, process, or service by trade name, trademark, manufacturer, or otherwise, does not necessarily constitute or imply its endorsement, recommendation, or favoring by the United States Government or the University of Calffornia. The views and opinions of authors expressed herein do not necessarily state or reflect those of the United States Government or the University of California, and shall not be used for advertising or product endorsenent purposes.

This report has been reproduced directly from the best available copy.

Available to DOE and DOE contractors from the Office of Scientific and Technical Information

P.O. Box 62, Oak Ridge, TN 37831

Prices avaitable from (615) 576-8401, FTS 626-8401

Available to the public from the National Technical Information Service

U.S. Department of Commerce 5285 Port Royal Rd. Springfield, VA 22161 


\title{
Monitoring Six-Phase Ohmic Heating Of Contaminated Soils Using Electrical Resistance Tomography
}

\author{
A. L. Ramirez, W. D. Daily \\ Lawrence Livermore National Laboratory \\ Livermore, $\mathrm{CA}$
}

\begin{abstract}
Electrical resistance tomography (ERT) was used to monitor six-phase ohmic heating used for the insitu remediation of volatile organic compounds from subsurface water and soil at the Savannah River Site, near Aiken, South Carolina. The changes in electrical conductivity caused by six-phase ohmic-heating in a clay layer located in the vadose zone were monitored during a period of approximately 2 months, before, during and after heating. From an array of electrodes located in 4 boreholes, we collected electrical resistivity data between five pairs of adjacent holes pairs. This data was used to calculate tomographs which showed the electrical conductivity changes along five vertical planes. The difference tomographs show the combined effects of moisture redistribution and heating caused by six-phase heating and vapor extraction. The tomographs show that most of the clay layer increased in electrical conductivity during the first 3 weeks of the 4 week long heating phase. At this time, the electrical conductivities near the center of the heating array were twice as large as the pre-heat conductivities. Then the electrical conductivity started to decrease for portions of the clay layer closest to the vapor extraction well. We propose that the conductivity decreases are due to the removal of moisture by the heating and vacuum extraction. Parts of the clay layer near the extraction well reached electrical conductivities as low as $40 \%$ of the pre-heating values. We propose that these regions of lower than ambient electrical conductivities are indicators of regions where the vapor removal by vacuum extraction was most effective. At the end of the heating phase, our estimates suggest that the clay saturation may have dropped to as low as $10 \%$ based on the observed conductivity changes.
\end{abstract}

\section{Introduction}

The remediation of soils and ground water contaminated with organic and inorganic compounds is an important objective of many environmental restoration efforts. A wide range of technologies is available and new technologies are being developed. Many of these remediation schemes can affect the contaminated volume in ways that are difficult to predict; therefore, it is advantageous to monitor the remediation so that its effectiveness can be assessed. We report herein on the use of electrical resistance tomography (ERT) to monitor underground soil heating coupled with vapor extraction when used to cleanup contaminated 
soils and water. ERT used either separately or in combination with other geophysical, hydrological or geochemical techniques can be a powerful tool in monitoring the interaction between the remediation process and the contaminated environment.

The Integrated Demonstration for VOCs in Soils and Groundwater at Non Arid Sites (VOCNAS) was undertaken by the Department of Energy (DOE) to demonstrate novel technologies for the in situ remedial cleanup of volatile organic compounds from saturated and unsaturated soil horizons at the Savannah River Site, South Carolina. The project used an array of six vertical wells containing heating electrodes to heat the contaminated soil and one central vapor extraction well to extract contaminants from the subsurface. The technique used during VOCNAS to heat the soil, and thereby thermally enhance the removal of TCE and PCE is referred to as six-phase ohmic heating (SPOH).

Electrical resistivity of soils is a function of moisture content, temperature, mineralogy (e.g. clay content) and water salinity (Hearst and Nelson, 1985). Heating causes moisture content, temperature, and fluid conductivity changes, all of which affect electrical resistivity. The successful application of ERT provides a two or three-dimensional view of the subsurface resistivity or conductivity distribution. This information helps us to understand the interaction between heating and the heterogeneous subsurface, the effects of heating on fluid flow, and the interaction between heating and other processes such as rainwater infiltration. Such insight is useful to understand remedial processes as well as the contaminant movement. Ground water flow is likely to influence contaminant mobilization and transport as well as heat transport, and geologic structure affects the flow of ground water and vapor. Underground imaging techniques reduce the need for the many boreholes that would otherwise be required to densely monitor such underground flow.

The demonstration of SPOH was performed by Pacific Northwest Laboratories (PNL) in cooperation with the Westinghouse Savannah River Technology Center (WSRTC). As part of the monitoring team, Lawrence Livermore National Laboratory (LLNL) was responsible for conducting ERT surveys between pairs of vertical boreholes to map the changes in electrical resistivity distribution. From these data, we infer changes, both spatial and temporal, in moisture content and in temperature. Based on these changes, inferences can be made regarding the influence of heating and geologic heterogeneity's on fluid movement and heat distribution.

The SPOH used six heating electrodes located on a hexagonal borehole pattern surrounding a central vapor extraction well. The electrodes were $6.1 \mathrm{~m}(20$.$) long and were located between$ depths of 7.01 and $13.1 \mathrm{~m}$ (23 and 43.) (Gauglitz et al., 1994a, 1994b). The boreholes intersected a clay rich horizon contaminated with TCE and PCE. A $3.05 \mathrm{~m}$ (10 ft.) thick clay zone beginning $9.14 \mathrm{~m}$ (30 ft.) from the surface was the target for the heating process because it contained a significant portion of the contamination present (Eddy-Dilek et al., 1994). The vapor extraction well was screened within the clay-rich zone to allow the removal of vaporized contamination using a vacuum extraction system. A detailed description of the SPOH demonstration is provided by Gauglitz et al .(1994a, 1994b).

The site is located near Aiken, South Carolina within the Department of Energy's Savannah River Site. The experimental site consisted of alternating units of sand, clay and gravel deposited in shallow marine, lagoonal or fluvial environments. The vadose zone is approximately $41 \mathrm{~m}$ (135 feet) thick. Clay layers are usually thin or discontinuous. The sand 
units ranged from fine to coarse grained and were, in general, moderately sorted with relatively little silt and clay. The silty clay units or clayey sand units exhibited relatively low permeability. Additional site details are provided by Eddy et al., (1991).

\section{Borehole Configuration and Data Collection:}

Figure 1 shows a plan view of the site. The ERT image planes, the heating electrode array, vapor extraction well, and other monitoring wells are also shown. Measurements were made between a series of four vertical boreholes drilled in the vicinity of the some of the heating boreholes and vacuum extraction well. The ERT boreholes (e1, e2, e3 and e4) were constructed by fixing stainless steel electrodes externally to the PVC casing; the borehole annulus was backfilled with the drill cuttings. A separate wire connected each electrode with the surface measurement system. All boreholes have 10 electrodes, evenly spaced between 3.1 and $16.8 \mathrm{~m} \mathrm{(10}$ and $55 \mathrm{ft}$.) depth. Crosshole resistivity surveys were performed between boreholes e 4 and $\mathrm{e} 1$ (referred to as plane e4e1, borehole e4 on the left side of the image), between boreholes e2 and e1 (plane e2e1, borehole e2 on the left side of the image), between boreholes e2 and e3 (plane e2e3, borehole e2 on the left side of the image), between boreholes e2 and e4 (plane e2e4, borehole e4 on the left side of the image), and between boreholes e3 and e4 (plane e3e4, borehole e3 on the left side of the image).

The heating demonstration was conducted in three phases: 1) a baseline vapor extraction phase lasting approximately 12 days, 2) a heating and vapor extraction phase lasting approximately 25 days, and 3 ) additional vapor extraction phase for six weeks after the heating was completed. Figure 2 shows the date when ERT surveys were conducted before and during the vapor extraction phase, and before, during the heating phase. One additional survey (not shown in Figure 2) was performed approximately two weeks after the heating phase was completed. This sequence of surveys was used to monitor the temporal behavior of the heating demonstration.

Electrical resistance tomography (ERT) is a technique for determining the subsurface electrical resistivity or conductivity distribution through measurement of injected currents and resulting electrical potential distributions in boreholes and at the surface. The bulk resistivity varies with moisture content and temperature for most soil/water systems. Resistivity typically decreases with increasing moisture content and increasing pore water temperature (Hearst and Nelson, 1985). Resistivity is also dependent on soil and water chemistry and other factors. For example, clay-rich zones are strongly conductive, and an important mechanism for electrical conduction is surface conduction along the double layer present on clay particles (Hearst and Nelson, 1985).

Cross borehole ERT is accomplished with a number of electrodes in electrical contact with the soil in each borehole. A known D.C. (direct current, polarity switched) current is applied to two electrodes and the resulting voltage differences are measured between other pairs of electrodes. Next, the current between is applied to two other electrodes and voltage differences are measured using electrode pairs not being used to inject the source current. Each ratio of measured voltage and current is a transfer resistance. This process is repeated until all the linearly independent combinations are measured. For $n$ electrodes there are $n(n-$ $3) / 2$ independent transfer resistances. These measurements for a cross-borehole survey are similar to those used in a conventional surface dipole-dipole resistivity survey. 
Calculating the distribution of resistivity in the vicinity of the boreholes, given the measured transfer resistances, is a highly nonlinear problem because the current paths are dependent on the resistivity distribution. However, this type of inversion has been widely studied [e.g., Henderson and Webster (1978), Pelton et al., (1978), Nariida and Vozoof (1984), Wexler et al. (1985), Brown et al. (1985), Isaacson (1986), Berryman and Kohn (1990)]. We will use the approach described in detail by LaBrecque (1994).

All the tomography planes were modeled by a finite element mesh 10 elements wide (between the boreholes) and 18 elements long (along the boreholes). Other elements were used to model the resistivity external to the region between the boreholes, although their values are poorly constrained by the data and therefore are not included in the image. In all reconstructions shown in the results section, only the elements modeled between the boreholes are displayed. After reconstruction, the tomographs are spatially smoothed to give the appearance of a continuous resistivity distribution. This, of course, doesn't improve resolution, which can be no better than one square element, $0.76 \mathrm{~m}(2.5 \mathrm{ft}) \mathrm{m}$ on a side.

\section{Discussion of Results:}

\section{Background Tomographs.}

In November 1993, before ohmic heating began, data were collected for imaging each of the 5 ERT planes. The reconstructed images are shown in Figure 3, arranged so that their common edges are adjacent but with the box formed by the 4 outside planes unwrapped to accommodate display on a flat page. The color scales are the same for each image to facilitate comparison. Each image consists of 180 pixels and each pixel is approximately 0.75 meter square, arranged 18 high and 10 across. Resolution is an unknown function of many factors including data accuracy, electrode geometry, electrode sampling schemes, position in the image plane and other factors. The resolution for each image is probably about $0.75 \mathrm{~m}$ along each borehole but is closer to $1.5 \mathrm{~m}$ near the image center.

The greatest value of these background images is for comparison with subsequent data. However, prominent features give us a view of the electrical properties at the site before heating began. The principal feature in these images is the conductive layer between about 30 to 40 foot depth that extends throughout the site. This is the clay-rich unit that is the target zone for the electrical heating. Electrical heating currents should be preferentially channeled by this electrically conducting layer. The resulting changes in these units are shown in the comparison images discussed later. This layer is most conductive near hole e4 at about 34 feet depth but a conductive zone extends toward the surface all the way to 10 feet depth. The hydrogeologic cross section of the site shows nearly continuous clay rich soil a few meters from e4 at heating electrode a2 between 40 feet and the surface. The only possible manifestation of this in the site cross section is two closely spaced clay stringers each about one foot thick and near 20 feet depth observed in the vent well.

\section{Three dimensional baseline tomograph}

The five ERT data sets collected prior to the start of heating were combined into a single data set to calculate the 3d tomograph shown in Figure 4. The reconstructed block shown is approximately $12 \mathrm{~m}$ wide, $6 \mathrm{~m}$ deep and $13.5 \mathrm{~m}$ tall and represents 972 cubic meters of soil. The approximate depth of the clay layer being treated is labeled in Figure 4. The 3-d result 
agrees well with the 2-d tomographs. Figure 4 shows various slices through the three dimensional block. One of the slices corresponds to the elevation of the center of the clay layer $10.67 \mathrm{~m}$ depth (35 ft depth) heated by the ohmic heating test. Note that the electrical resistivity of the clay layer varies laterally and that the thickness of the clay varies significantly. This lateral heterogeneity in the clay resistivity probably affected the heating and vapor extraction as will be discussed later. It also probably affects the flow paths of rainwater infiltrating from the ground surface. Note that rain water or contaminants that penetrate the subsurface will flow generally downward through the sand layers until they reach the contact between the clay and overlaying sands. Then, these fluids are likely to flow along the sandclay contact.

Implications of electrical conductivity heterogeneities

The region of higher conductivity (and inferred higher clay content) near e4 may have a number of implications pertaining to the expected behavior of SPOH : 1: The relative locations of the highly conductive clay near e4 and the extraction well suggest that the region of influence for the extraction well is likely to be larger to the North and East of the well than to the South and West. 2) The clays in the vadose zone at the experimental site are known to hold a higher fraction of the total moisture than the surrounding sand layers (Eddy-Dilek et al., 1993). This suggests that the thermal mass of the clay is proportionally larger than the thermal mass for the sand layers and that to reach the same temperature more energy needs to be delivered to the clays than to the sands. 3 ) The approximately twenty fold contrast ( 1.3 order of magnitude observed in Figures 3 and 4) in electrical conductivity contrast between the sand layers and the clay suggests that there can be significant focusing of the electrical currents towards the clay and away from the sand. Heating electrode phases a2 and b1 (shown in Figure 1) are in the area were the conductive clay zone is the thickest, whereas, the other four phases are located in regions where the clay is thinner.

We use a simple model to illustrate the effect of conductivity heterogeneities on electrical power dissipation. Consider a cube of soil, one meter on a side. On two opposing sides of this cube, there are flat plate electrodes which completely cover each side. In this case, the resistivity $\rho$ of the cube in the direction orthogonal to the electrodes is (Telford et al., 1976):

$$
\rho=R A / l
$$

where $R=$ resistance, $A=$ cross-sectional area $\left(1 \mathrm{~m}^{2}\right)$ and $I$ is the length of the cube $(1 \mathrm{~m})$. If we have two cubes with resistivities $\rho_{1}$ and $\rho_{2}$, and we apply the same voltage to each cube and make a current measurement, we can calculate the power applied to each. The power dissipated in a layer is:

$$
P=I^{2} R
$$

where $I$ is the current. Given that $I=\frac{V}{R}$ where $V$ is the voltage, then,

$$
P=\frac{V^{2} l}{A \rho}
$$


This equation shows that the power dissipated in a layer will be inversely proportional to the resistivity of the layer. The resistivity contrast between the sand and clay units at the experimental site typically ranges from ten to twenty. Thus, if we let $\rho_{2}$ equal to 1 (the equivalent to the clay layer at the experimental site) and $\rho_{1}$ equal 20 (the equivalent of the sand layers), we can see that equation 1 predicts that the power dissipated in the clay will be 20 times higher than in the sands. Clearly the model described above is much too simple to properly represent the current flow regime at the experimental site. Factors such as electrode size, electrode array configuration, soil layer geometry and other factors are not accounted for in a realistic way. A much more complex model would have to be used to properly account for all these factors; the use of such a model is beyond the scope of our study. However, the model used here helps to demonstrate that, given a twenty fold contrast in electrical resistivity, significant variability in power dissipation may occur through regions where large contrasts in electrical conductivity exist, such as between adjacent sand and clay layers.

\section{Comparison Tomographs.}

We will compare images using pixel by pixel differences between the baseline tomographs and the subsequent images. Differences are used for two reasons: (1) to remove the geologic spatial variability which does not change with time during heating and (2) to highlight the regions of changing conductivity and therefore the heated zones. We have used the same color scale for electrical conductivity (the inverse of resistivity) change in each image plane to facilitate spatial comparisons.

Vapor extraction (without heating) began on 10/19/93 and continued to $11 / 3 / 93$. All five ERT planes were sampled on 10/19 and 10/20/93. The surveys were repeated on 11/1/93 near the end of the vapor extraction phase. Figure 5 shows that the electrical conductivity of the clay layer of interest changed a small amount during the vapor extraction phase. These changes are 4 to 5 times smaller than the changes observed during heating (to be presented later). We believe that Figure 5 shows changes that may be near to the detection limits for ERT. However, these images begin to establish a pattern of behavior that continued into the heating phase. There are negative conductivity differences (i.e., conductivity decreases relative to the conductivity measured on 10/19/94) close to the vapor extraction well in plane e4e1 at the elevation of the clay layer. Decreasing moisture content is the condition that most likely would explain these decreases in conductivity. The conductivity differences suggest that moisture has been removed by the vapor extraction process, thereby decreasing the electrical conductivity. Another region of small negative differences within the clay observed along plane e2e3. Plane e2e4 and the top of plane e3e4 shows positive differences in electrical conductivity. Increases in the moisture content of soils typically result in conductivity increases (Hearst and Nelson, 1985). We speculate that rainwater infiltration (note that 3.3 inches of rain fell on 10/29/94, 3 days before the 11/01/94 ERT survey was conducted) increased the moisture content of this area.

Electrical heating began on 11/3/93 and continued until 12/1/93 1993, with regular 6 hour interruptions due to service of the generators which provided the electrical power. Vapor extraction also continued during this phase. Five sets of electrical resistance tomographs were taken when the SPOH electrical generators were being serviced so as to sample representative periods during the entire period of heating: 11/1/93 are the background images; $11 / 10 / 93$ were obtained after only about $10,000 \mathrm{kwh}$ (one tenth to total) of heating; $11 / 17 / 93$ were obtained after not quite half the total electrical heating energy was applied; $12 / 1 / 93$, at the 
end of heating after $100,000 \mathrm{kwh}$ electrical was added; $12 / 14 / 93$, two weeks into the rebound from the thermal heating.

Ionic conduction in the pore water and at the solid-water double layer interface are the dominant paths for electric current flow (Keller and Frischnecht, 1966). During electrical heating, two main mechanisms are influencing changes in electrical conductivity: changing ion mobility as a result of temperature change and ion availability resulting from changing moisture content. Early in the heating process, ohmic heating deposits energy in the pore water, resulting in a temperature increase. As long as the availability of ions (net moisture content) doesn't change, the electrical conductivity will increase relative to the background resistivity. As the conductivity of the clays increase, the electrical contrast between them and the surrounding soils increases and the currents used for electrical heating tend to be more confined to the clays. Eventually, the formation begins to loose water by evaporation. This water loss is delayed by the low permeability of the clays. Eventually, water vapor moves down the pressure gradient, through the clays to the more permeable sands and then out of the system. With this water loss, available conduction ions become isolated in disconnected water pockets, the electrical conductivity eventually decreases and the formation dries out. To summarize, as the formation is heated we expect an initial increase in electrical conductivity above background followed by a decreasing conductivity. The final conductivity may be above or below the initial value, depending on the final temperature, water and soil chemistry and moisture content.

Figure 6 shows pixel by pixel differences between the baseline images of Figure 3 and the subsequent images early in the heating phase. Here also we have used the same color scale for electrical conductivity (the inverse of resistivity) change in each image plane and for each day to facilitate both temporal and spatial comparison.

There are significant changes in electrical conductivity during electrical heating and cool-down, especially in the clays. We estimate that noise sources can account for variability in the images of only $5 \times 10^{-4} \mathrm{~S} / \mathrm{m}$ and as early as $11 / 10 / 93$, measured values had changed by more than this amount with a band of increased conductivity centered on the clay layer between 30 and 40 feet depth. This is clearly seen on 11/10/93 data after 7 days and approximately $10,000 \mathrm{kwh}$. This data was taken before any water vapor had been removed using the central vapor extraction well. The conductivity anomaly appears extended throughout portions of the image planes that are within the heating well pattern and confined mostly to the level of the clay. The thermocouple data (the measurements near image planes are superimposed on the images) support this interpretation.

By 11/17/94 (Figure 7), the images suggest that the electrical conductivity changes have gotten larger. There is an increase in electrical conductivity contrast between the target zone and the region above and below it and there is a spreading of the affected regions, especially vertically along the heating electrodes $a 1$ and b1 and the extraction well. There is no sign of decreasing conductivity in any image plane as might be expected from drying even though some drying has certainly occurred; temperatures of the clay in wells PT1 and PT2 (see Figure 7 had reached $100 \mathrm{C}$ approximately two days earlier (Gauglitz et al., 1994b). The average phase resistance in the electrical heating system was on a steady decline until it leveled off on approximately 11/17/94; vapor extraction from the central extraction well began approximately 6 weeks before the data for these images was taken. 
The ERT images in Figure 7 show that the thickest region of conductivity increases and largest magnitude of conductivity change occur near borehole e 4 along planes e4e1 and e3e4. We propose the following explanation for this condition. The baseline tomographs in Figures 3 and 4 show here a much thicker conductive layer with the highest electrical conductivity measured within the survey region. Based on these observations, we believe that this region has a higher clay content, is thicker and is less permeable than regions to the North and East. At temperatures near boiling, this region near e4 was less affected by the vapor extraction well and thus retained a higher saturation than other regions to the North and East. As a result of the higher moisture content, the conductivity increases near e 4 were the largest because there were more ions available to carry the electrical charges.

The comparison images from 12/1/93 (Figure 8) show a completely different character from the previous images. Most conspicuous is a large zone centered on the clay zone and extending horizontally through plane e4e1 and into plane e2e1 in which electrical conductivity is less than the pre-heat conductivity. In addition, there are extensive regions in all planes, but especially adjacent to well e4 which now show a conductivity that has returned closer to initial values (shows smaller increases from background than previous images). Both of these conditions suggest that by this time the clays have started to dry substantially. There is ample supporting evidence for this conclusion. First, the formation temperatures in ow1, ow2, pt1 and pt2 (all the thermocouple wells inside the heating pattern) had reached boiling for as long as 2 weeks. Second, water vapor had been extracted from the central extraction well over approximately the same time period. Third, the average phase resistance for the heating electrodes begins to increase on about November 25 and this is a sign of significant bulk resistivity increase in the subsurface (Gauglitz et al., 1994b). Fourth, thermocouple readings from pt1 and pt2 show that temperatures in the clay had dropped to as low as $77 \mathrm{C}$ in the region where the largest conductivity decreases were detected. Note that the temperatures in ow1 are significantly higher than in pt1 and pt2 in spite of the fact that the distance between all three boreholes and the extraction well is the same. We propose that the influence of the vapor extraction well was the strongest to the North and East of e4 and caused the largest reduction in atmospheric pressure. As result, the lowered the boiling temperature of water in this region caused lower temperatures to be observed in pt1 and pt2.

Another feature in the images of $12 / 1 / 93$ is the spreading of the heated zone. In all the image planes there we see an increase in conductivity above and below the target clay zone which is consistent with elevated temperatures in those regions and is confirmed by the thermocouple data. This effect might be from thermal conduction of the heat out of the clay into the surrounding formation or it may be from direct ohmic heating of the sands outside of the target zone. In the images adjacent to well e4 these new effects outside the clay are largest in magnitude and extend upward beyond the 10 foot depth.

The comparison images of 12/14/93 (Figure 9) show a decrease in each plane from the maximum conductivity reached in that plane. This is evidence for dehydration of the clays in every plane. However, the electrical conductivity decrease is not uniform across the clays and is most prominent in planes e2e1 and e4e1. We assume dehydration is most complete at the location of this resistive anomaly (in comparison to the background images). Although electrical heating was terminated on 12/2/93, vapor extraction from the vent continued into January 1994. The proximity of the anomaly to the extraction well suggests that moisture within a few meters of the vent well was extracted from the formation after active heating 
stopped but while temperatures were still elevated. The shape of the anomaly probably reflects the natural heterogeneity in the heating as well as in the pathways required for drying.

An estimate of the heated volume based on the ERT results is not practical because the image planes do not adequately cover the entire heating pattem. However, the ERT images give a detailed picture including the lateral and vertical extent in the planes imaged and with more complete coverage these data could be used for such an calculation of heated volume.

\section{Resistivity Changes and Saturation Changes:}

The resistivity differences shown in Figure 8 can be used to estimate the saturation changes caused by heating. The work of Waxman and Thomas (1954 a, $1954 \mathrm{~b})$ shows that clay conductance contributes a significant fraction of total conductance under some conditions and modifies the saturation - porosity - resistivity relationship. The conductance effects become more significant with increasing clay content, decreasing $S_{w}$ (saturation), and increasing $R_{w}$ (water resistivity). The model proposed by Waxman and Thomas assumes: 1) a parallel conductance mechanism with free electrolyte and clay-exchange cation components, and 2) an exchange cation conductance, $B$ that depends on the equilibrating electrolyte concentration and temperature. At a fixed temperature, $B$, approaches a maximum value for low $R_{w}$ and a minimum value for high $R_{w}$. The exchange cations provide a conductor for electrical current separate from, but parallel to, the conduction path through the pore space. We use this model to explain the observed decreases in bulk resistivity caused by heating and drying.

Chesnut and Cox (1978) derived the following formula from the work of Waxman and Thomas:

$$
R_{t}=\frac{\left(\phi S_{w}\right)^{-v} R_{w}}{1+R_{w} B Q_{v o}\left(\phi S_{w}\right)^{-1}}
$$

where:

$R_{W}=$ water resistivity, ohm-cm

$R_{\mathrm{t}}=$ resistivity of water bearing sediment (or rock), ohm-cm

$\phi=$ fractional porosity

$S_{W}=$ water saturation as fraction of pore volume

$\mathrm{B}=$ equivalent conductance of exchangeable cations,

$\left(\mathrm{cm}^{3} / \mathrm{meq}\right) /(\mathrm{ohm}-\mathrm{cm})$

$Q_{v b}=$ cation exchange capacity of sediment, meq per $\mathrm{cm}^{3}$ of bulk volume

$v=$ combined saturation and porosity exponent, typically about 2

For the case of the clay layer at the experimental site, we have a fairly high $R_{W}$ and "dirty" (i.e. high clay content and a fairly large cation exchange capacity) sediments, for which the second term in the denominator of the modified Waxman-Smits equation is large compared to unity. For large $R_{W}$, the exchange-ion conductance term, $B$, approaches $0.17 \mathrm{Bmax}$, which is a function of temperature only. Then, using equation 2 , the ratio of resistivity at temperature $t_{1}$ and a water saturation of $S_{w 1}$ (before heating) to the resistivity at $t_{2}$ and a water saturation of $\mathrm{S}_{\mathrm{w} 2}$ (after heating) is: 


$$
\frac{R_{t 1}}{R_{t 2}} \approx \frac{\left(S_{w 1}\right)^{-1}}{\left(S_{w 2}\right)^{-1}} \times \frac{B_{\max 2}}{B_{\max 1}}
$$

$R_{t 1}$ is the resistivity before heating and $R_{t 2}$ is the resistivity after heating. $B_{\max 1}$ is the $B_{\max }$ corresponding to $t_{1}$ and $B_{\max 2}$ is the $B_{\max }$ corresponding to $t_{2}$. To convert equation 3 from resistivity to conductivity, we let $C_{t 1}=\left(R_{t 1}\right)^{-1}$ and $C_{t 2}=\left(R_{t 2}\right)^{-1}$ equation (3) becomes:

$$
\frac{C_{t 2}}{C_{t 1}} \approx \frac{\left(S_{w 1}\right)^{-1}}{\left(S_{w 2}\right)^{-1}} \times \frac{B_{\max 2}}{B_{\max 1}} .
$$

We can use equation 4 to make estimates of saturation change caused by heating if we assume some sediment properties. We will assume that initial saturation $\left(\mathrm{S}_{\mathrm{w} 1}\right)$ of the clay unit was 0.82 ; this is the average saturation for the clay unit along a borehole in the vicinity of the heating electrode array based on saturation values of core samples reported by Eddy-Dilek et al., (1993). We also know that the initial temperature is $18^{\circ} \mathrm{C}$. $B_{\max }$ as function of temperature is obtained from Waxman and Thomas (1974). Figure 10 shows plots of saturation versus conductivity ratios (after heating (hot) / before heating (cold)) as a function of saturation $\left(S_{w 2}\right)$ and temperature. The figure shows, for example, that for a temperature of $100{ }^{\circ} \mathrm{C}$, the conductivity ratio becomes one for a saturation of about 0.22 . This means that given a temperature of $100^{\circ} \mathrm{C}$ the conductivity would increase due to heating as long as the saturation $\left(\mathrm{S}_{\mathrm{w} 2}\right)$ was greater than $0.22(22 \%)$. We consider these saturation predictions as only rough estimates because of the number of assumptions that have to be made.

In planes e2e 3 and e3e4 we only observed conductivity increases along the clay layer. Where the temperature reached $100{ }^{\circ} \mathrm{C}$, we conclude that the saturation during the test had to be greater than $22 \%$. The tomographs collected near the end of the heating phase (12/01/94) shown in Figure 8 show that the clay layer in planes e2e3 and e3e4 had a ratio ranging

between 1.4 and 1.8. These ratios suggest that $S_{\text {w2 }}$ was between 0.3 and $0.4(30-40 \%)$ given a temperature of $100 \mathrm{C}$. Along planes $\mathrm{e} 4 \mathrm{e} 1$ and e2e1 resistivity ratios as low as 0.38 were observed within the clay. In this case, $S_{\mathrm{w} 2}$ would probably be less than 0.1 (about 0.09 ) where the temperatures reached $100 \mathrm{C}$. However, thermocouples readings from well PT2 reported by Gauglitz et al (1994b) show that parts of the clay layer may have been at temperatures as low as $88 \mathrm{C}$. At this lower temperatures the predicted $S_{\mathrm{w} 2}$ would be about $0.1(10 \%)$.

\section{Summary and Conclusions:}

We have described work where we use electrical resistance tomography to monitor in-situ soil remediation at the Integrated Demonstration for VOCs in Soils and Groundwater at Non Arid Sites. The changes in electrical conductivity caused by six-phase ohmic-heating in a clay layer located in the vadose zone were monitored during a period of approximately 2 months; before, during and after heating. From an array of electrodes located in 4 boreholes, we collected electrical resistivity data between five pairs of adjacent holes pairs. This data was used to calculate tomographs which showed the electrical conductivity structure along five vertical planes. Electrical conductivity differences were then calculated by subtracting pixel by pixel tomographs collected during and after heating from tomographs obtained before heating. We then fit these planes together for an overall picture of the effects of heating. 
In general, we expected the difference tomographs to show the combined effects of moisture redistribution and heating caused by six-phase heating and vapor extraction. We expected to see a more or less symmetrical zone of increased conductivity about the vapor extraction well grow as the clay temperatures rose and the mobility of ions within the clay increased. At some point, a zone of decreased conductivity was then expected to develop as the clay became almost completely dry and the film of water within the pore structure became discontinuous.

The ERT images suggest a somewhat more complex process contributing to the results. The heating process in all probability caused moisture re-distribution in the form of drying and water condensate. Drying will cause the electrical conductivity to go down, while temperature increases and condensate formation will cause the conductivity to increase. The tomographs show most parts of the clay layer exhibiting electrical conductivity increases during the first 3 weeks of the heating phase. In soils having the relatively high cation exchange capacity of the clay layer at the experimental site, the electrical conductivity typically goes up as the temperatures in the clay layer increase to near-boiling so long as the saturation of the clay remained near $22 \%$ or greater. When the saturation of the clay drops below $22 \%$ at a temperature of $100{ }^{\circ} \mathrm{C}$, the conductivity decreases relative to the initial value. Conductivity decreases in planes e4e1 and e2e1 are probably associated with regions in the clay that dried out below the $22 \%$ saturation threshold to as low as $9 \%$. This region of enhanced drying starts a few feet North of the extraction well and extends to the North to borehole e1 and to the East to borehole e2. The electrical conductivity of this region continued to decrease after the heating phase concluded and while vapor extraction continued.

The ERT images show significant vertical and lateral variability in the conductivity differences observed. We believe that this variability is due to primarily to the natural vertical and lateral variability in the electrical conductivity and permeability of the clay layer. The largest magnitude conductivity changes occurred in the thickest and most electrically conductive portions of the formation located near borehole e4. This region also showed the widest zone of conductivity increases observed. We believe that these heterogeneities had a significant impact on the behavior of heating and extraction process. Based on these observations, we propose that the clay layer becomes less clayey and more permeable towards e1 and e2. This condition would allow the vapor extraction well to preferentially pull gases from regions to its North and East, thereby enhancing moisture and contaminant removal from this area. The vacuum extraction would also tend to preferentially lower gas phase pressure in this region to below ambient, thereby resulting in a decreased boiling temperature. Permeability variations in the clay probably affected the removal of moisture (and other gases) and to a lesser extent may have affected the dissipation of electrical power and heat distribution.

\section{Acknowledgments:}

We recognize the contributions of the following colleagues at Lawrence Livermore National Laboratory (LLNL), Pacific Northwest Laboratories (PNL) and at the Westinghouse Savannah River Technology Center. WSRTC colleagues Tim Jarosch and Carol Eddy-Dilek, helped to plan, coordinate and implement this work, provided other site data and provided valuable suggestions regarding data interpretation. Phil Gauglitz (PNL) was the principal investigator for the six-phase ohmic heating test. John Carbino (LLNL) provided technical assistance before and during field operations; Jane Beatty provided programming support. Jesse Yow 
(LLNL), Alan Levy (LLNL), and Terry Walton (WSRTC) helped to develop, plan, and manage this work. Phil Gauglitz (PNL) and Robin Newmark (LLNL) reviewed this report and helped to improve it substantially. This work was sponsored by the Office of Technology Development, U.S. Department of Energy.

Work performed under the auspices of the U. S. Department of Energy by the Lawrence Livermore National Laboratory under Contract W-7405-Eng-48.

\section{References:}

Berryman, J. G., and R. V. Kohn 1990, "Variational Constraints for Electrical-Impedance Tomography," Phys. Rev. Lett. 65, 325-328.

Brown, B. H., D. C. Barber, and A. D. Seagar 1985, "Applied Potential Tomography: Possible Clinical Applications," Clin. Phys. Physiol. Meas. 6, 109-121.

Chesnut, D.A. and D.O. Cox, (1978) "Log Analysis in a Rocky Mountain Heavy Oil Reservoir," SPWLA Nineteenth Annual Logging Symposium, June 13-16.

Daily, W. D., and A. L. Ramirez, 1993, Electrical Resistance Tomography During In Situ TCE, Remediation at the Savannah River Site, Lawrence Livermore National Laboratory, UCRL-JC112326, Livermore CA, submitted to Journal of Applied Geophysics.

Eddy, C. A., B. B. Looney, J. M. Dougherty, T. C. Hazen and D. S. Kaback, 1991 Characterization of the Geology, Geochemistry, Hydrology and Microbiology of the In-Situ Air Srtipping Demonstration Site at the Savannah River Site (U), Westinghouse Savannah River Company WSRC-RD-91-21, Aiken, South Carolina.

Eddy-Dilek, C. A.,T. R. Jarosch, C. B. Fliermans, B. B. Looney, and W. H. Parker, 1993, Characterization of the Geology, Geochemistry and Microbiology of the Radio-Frequency Heating Demonstration Site at the Savannah River Site, Westinghouse Savannah River Company, WSRC-TR-93-459, Aiken, South Carolina.

Eddy-Dilek, C. A., Jarosch, T. R., Keenan, M. A., Parker, W. H., Poppy, S. P., Simmons, J. S., 1994, Characterization of the Geology and Contaminant Distribution at the Six Phase Heating Demonstration Site at the Savannah River Site: Westinghouse Savannah River Company, WSRC-TR-93-678, Aiken, South Carolina.

Gauglitz, P. A., J. S. Roberts, T. M. Bergsman, S M. Caley, W.O. Heath, M. C. Miller, R. W.,Moss, R. Schalla, T. R. Jarosch, C. A. Eddy-Dilek, and B. B.Looney, 1994, Six-Phase Soil Heating Accelerates VOC Extraction from Clay Soil, Pacific Nortwest Laboratory Rept. \# PNLSA-24298, Richland, WA, proceedings of Spectrum '94: International Nuclear and Hazardous Waste Management, Atlanta, Georgia, August 14-18, 1994. (a)

Gauglitz, P. A., J. S. Roberts, T. M. Bergsman, S M. Caley, W.O. Heath, M. C. Miller, R. W. Moss, R. Schalla, M. H. Schendler, T. R. Jarosch, C. A. Eddy-Dilek, and B. B.Looney, 1994, Field Test of Six-Phase Soil Heating at the Savannah River site, Pacific Nortwest Laboratory 
Rept. \# PNL-SA-24002, Richland WA, submitted to the Thirty-Third Hanford Symposium on Health and The Environment, Richland, WA, Nov. 7-11, 1994 (b).

Hearst, J. R. and P.H. Nelson, 1985, Well Logging for Physical Processes, McGraw Hill Book Company, New York.

Henderson, R., and J. Webster, 1978, "An Impedance Camera for Spatially Specific Measurements of the Thorax," IEEE Trans. Biomed. Eng. BME-25, 250.

Isaacson, D., 1986, "Distinguishability of Conductivities by Electric Current Computed Tomography," IEEE Trans. Medical Imaging MI-5(2), June.

LaBrecque, D. J., M. Milletto, W. Daily, A. Ramirez, and E. Owen, 1994, The effects of noise on Occam's Inversion of Resistivity Tomography Data, accepted for publication in Geophysics.

Nariida, C. S., and K. Vozoof 1984, "Two-Dimensional DC Resistivity Inversion for DipoleDipole Data, IEEE Trans. on Geoscience and Remote Sensing GE-22(1), 21-28.

Pelton, W. H., L. Rijo, and C. M. Smith, Jr. 1978, "Inversion of Two-Dimensional Resistivity and Induced-Polarization Data, Geophysics 43(4), 788-803.

Ramirez, A., W. Daily, K. LaBrecque, E. Owen and D. Chesnut, 1993, "Monitoring an Underground Steam Injection Process Using Electrical Resistance Tomography", Water Resources Research, 29(1), 73-87.

Telford, W.M., L.P. Geldart, R. E. Sheriff, D. A. Keys, 1976, Applied Geophysics, Cambridge University Press, Cambridge, U.K.

Waxman, M.H. and E.C. Thomas, 1974 a, "Electrical Conductivities in Shaly Sands - I. The Relation Between Hydrocarbon Saturation and Resistivity Index; . The Relationship between Hydrocarbon Saturation and Resistivity Index," Journal of Petroleum Technology (Feb.) 213218; Transactions AIME, 257.

Waxman, M.H. and E.C. Thomas, 1974 b, "Electrical Conductivities in Shaly Sands - II. The Relation Between Hydrocarbon Saturation and Resistivity Index; II. The Temperature Coefficient of Electrical Conductivity," Journal of Petroleum Technology (Feb.) 218-225; Transactions AIME, 257.

Wexler, A., B. Fry, and M. R. Neuman (1985), "Impedance-Computed Tomography Algorithm and System," Appl. Optics 24, 3985-3992. 


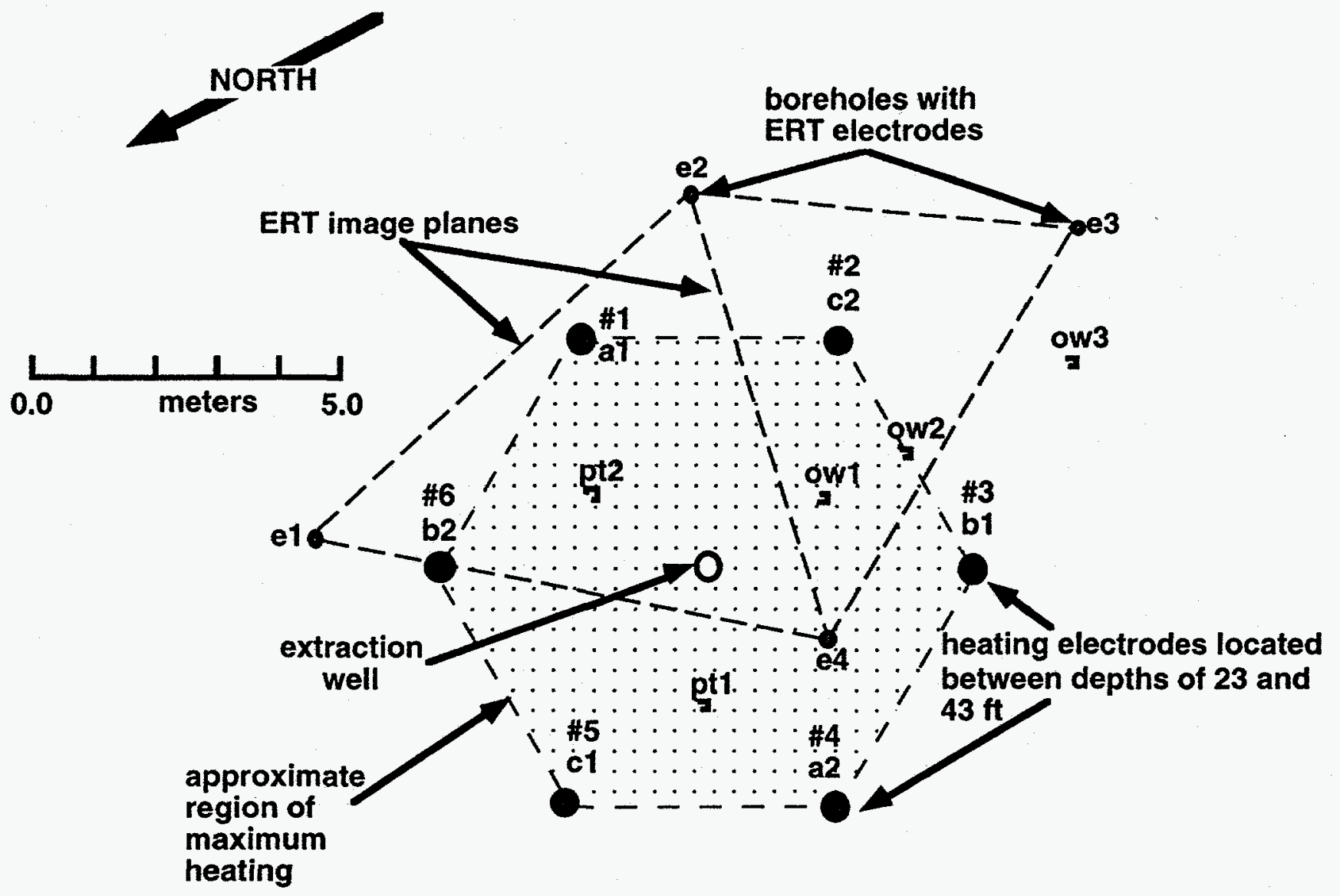

Figure 1. Plan view of the experimental site showing the location of the boreholes used for ERT (e1, e2, e3, e4), extraction well and the ohmic heating electrodes. The clay layer targeted for this demonstration is located between 9.14 to $12.5 \mathrm{~m}$ ( 30 and $41 \mathrm{ft}$ ) of depth 


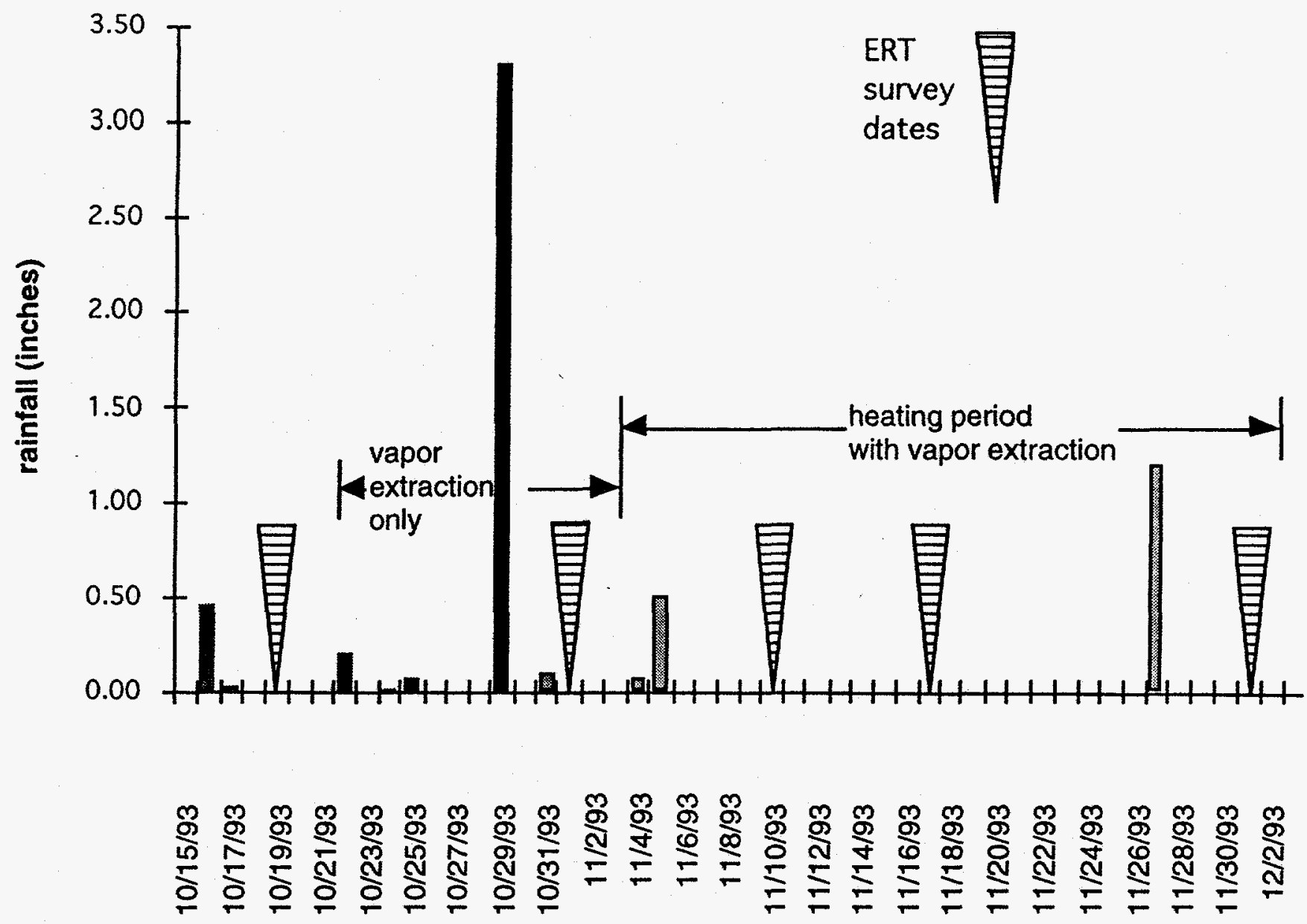

Figure 2. This figure shows the rainfall measured before and during the heating test and the times during which ERT surveys were performed. Rainfall data was provided by the Westinghouse Savannah River Technology Center. Electrical heating began on 11/3 with a few days of testing at lower power levels. Between 11/7 and 12/2/93 an average power of 200 kW was applied to the electrode array (Gauglitz et al., 1994b). A second period of vapor extraction (not shown in the figure) was performed after the heating phase concluded and additional ERT data was collected. 


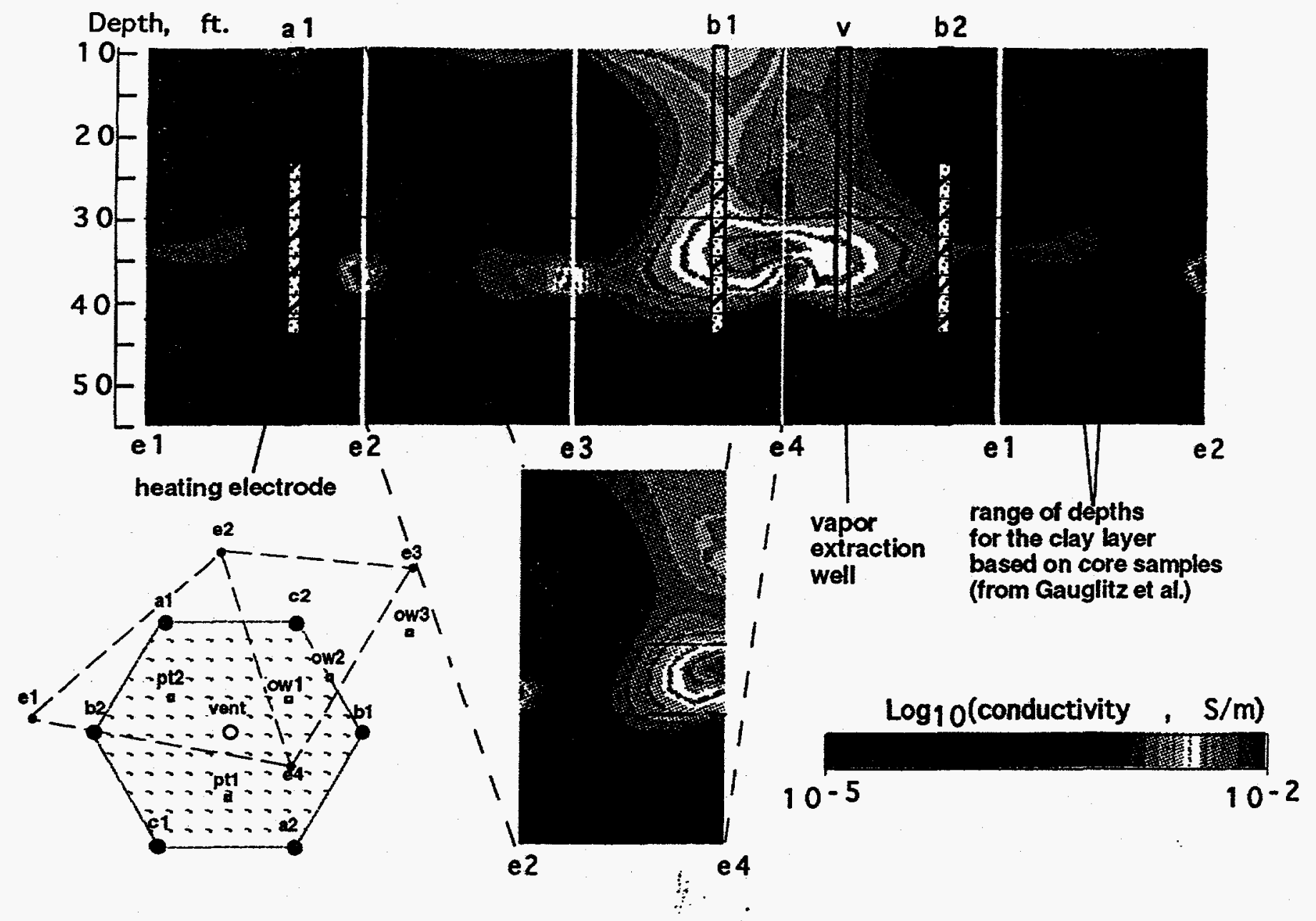

Figure 3. Two dimensional ERT images representing the electrical conductivity structure before heating began. These images were calculated using data collected on 11/1/93, a few days prior to the start of heating. The locations of the ERT boreholes (e1, e2, e3, e4), heating electrodes and the extraction well were projected to the closest ERT plane. These projected locations are shown for reference. 


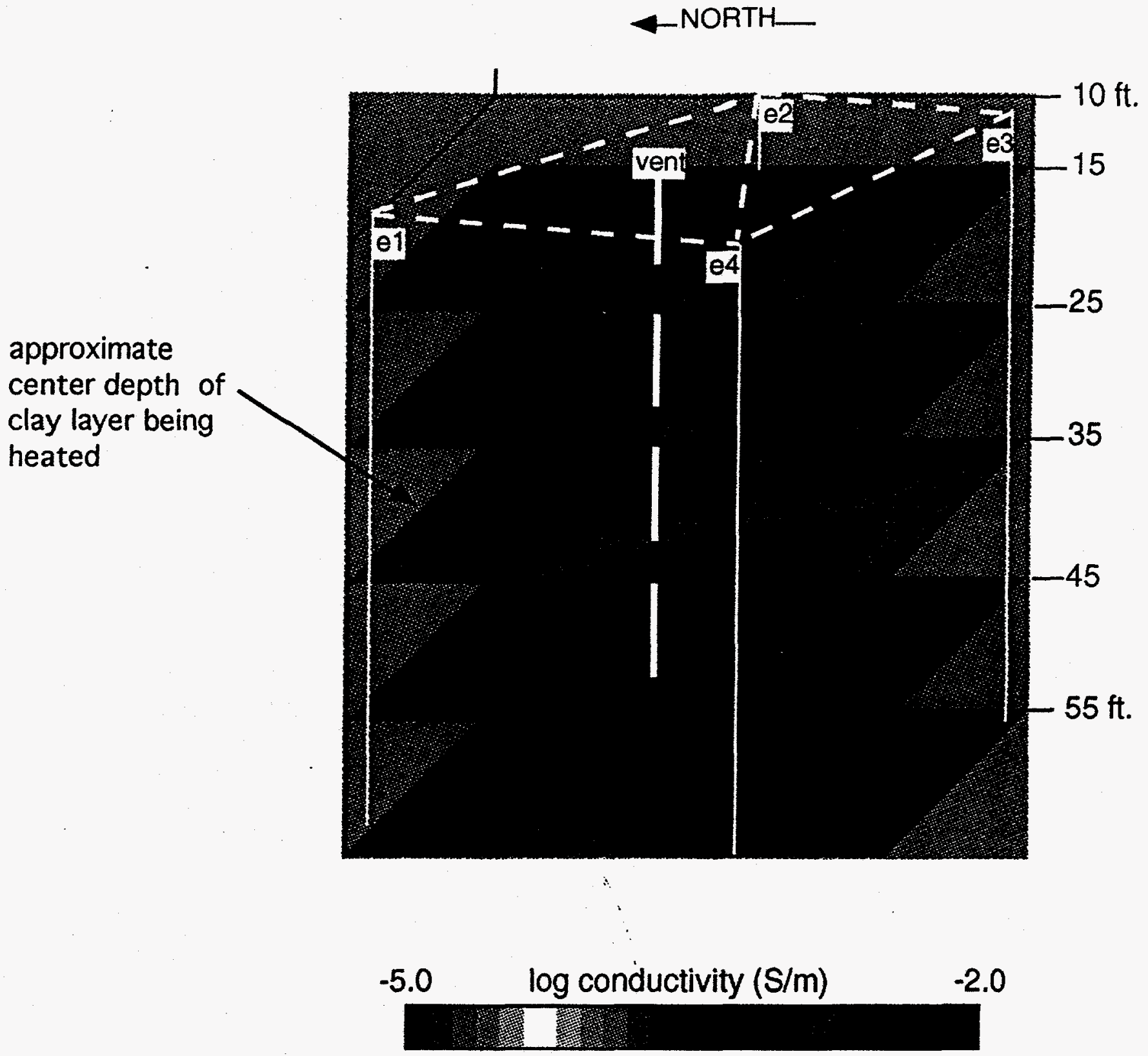

Figure 4 Three dimensional ERT image representing electrical conductivity structure before heating began. The three dimensional block has been sliced at several depths so that the conductivity along the East-West axis can be observed. This image was also calculated using the data collected on 11/1/93, but this time a fully three-dimensional ERT algorithm was used. The locations of the ERT boreholes and the extraction borehole (labeled "vent") are also shown for reference. The color scale shows the most conductive layers (typically clays and silts) in blue and the least conductive layers (typically sands) in green. Note that the region of highest conductivity is located at the elevation of the clay layer and that this region extends upwards to at least $4.57 \mathrm{~m}$ ( $15 \mathrm{ft}$.) depth. Also note that there is significant lateral variability in the conductivity of the clay layer at $10.67 \mathrm{~m}(35 \mathrm{ft})$ of depth. 


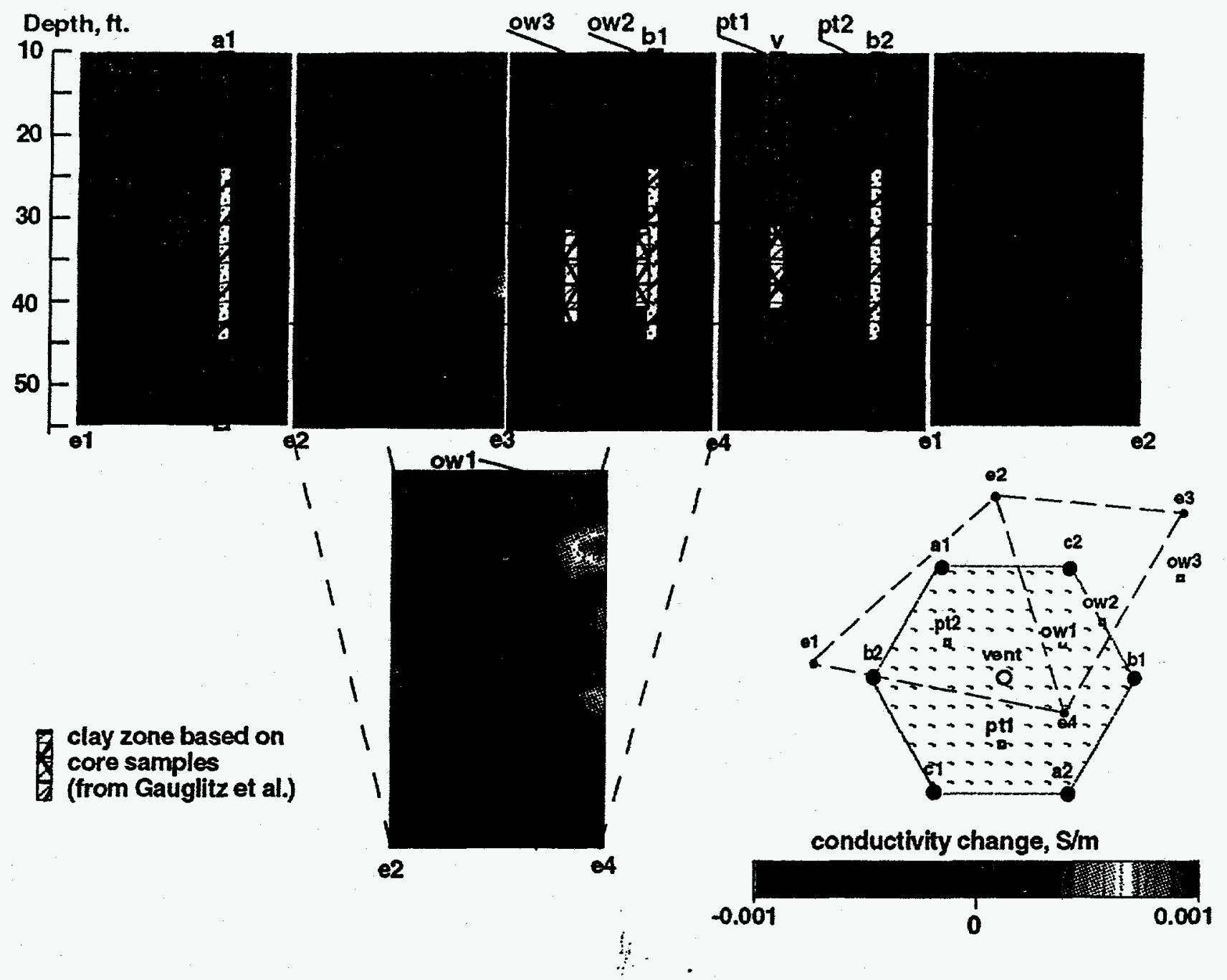

Figure 5. Two dimensional conductivity difference images representing the changes in electrical conductivity observed during the vacuum extraction phase prior to the start of heating These images were calculated by subtracting the 10/19/93 tomographs from the 11/1/93 tomographs collected a few days prior to the start of heating. The locations of the ERT boreholes (e1,e2, e3, e4), heating electrodes and the extraction well were projected to the closest ERT plane. These projected locations are shown for reference. The location of the clay layer inferred by Gauglitz et. al (1994b)based on core samples is also shown. 


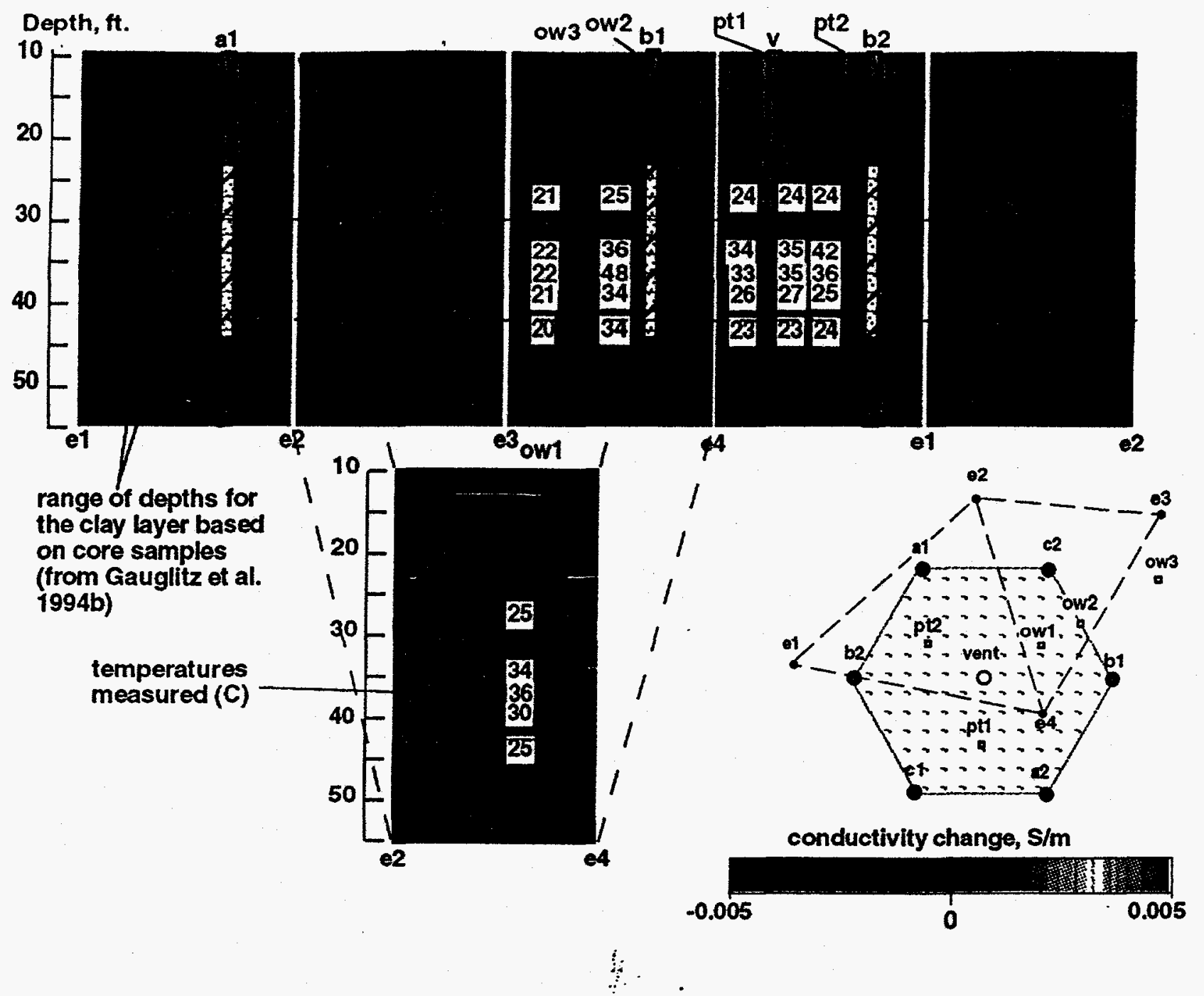

Figure 6. Two dimensional conductivity difference images representing the changes in electrical conductivity observed after approximately seven days of heating. These images were calculated by subtracting the 11/01/93 tomographs (collected a few days prior to the start of heating) from the 11/10/93 tomographs. The locations of the ERT boreholes $(e 1, e 2, e 3, e 4)$, heating electrodes and the extraction well were projected to the closest ERT plane. These projected locations are shown for reference. Also shown are temperatures (degrees C) measured by Gauglitz et al (1994b) along various boreholes (ow2, ow2, pt1, and pt2). 


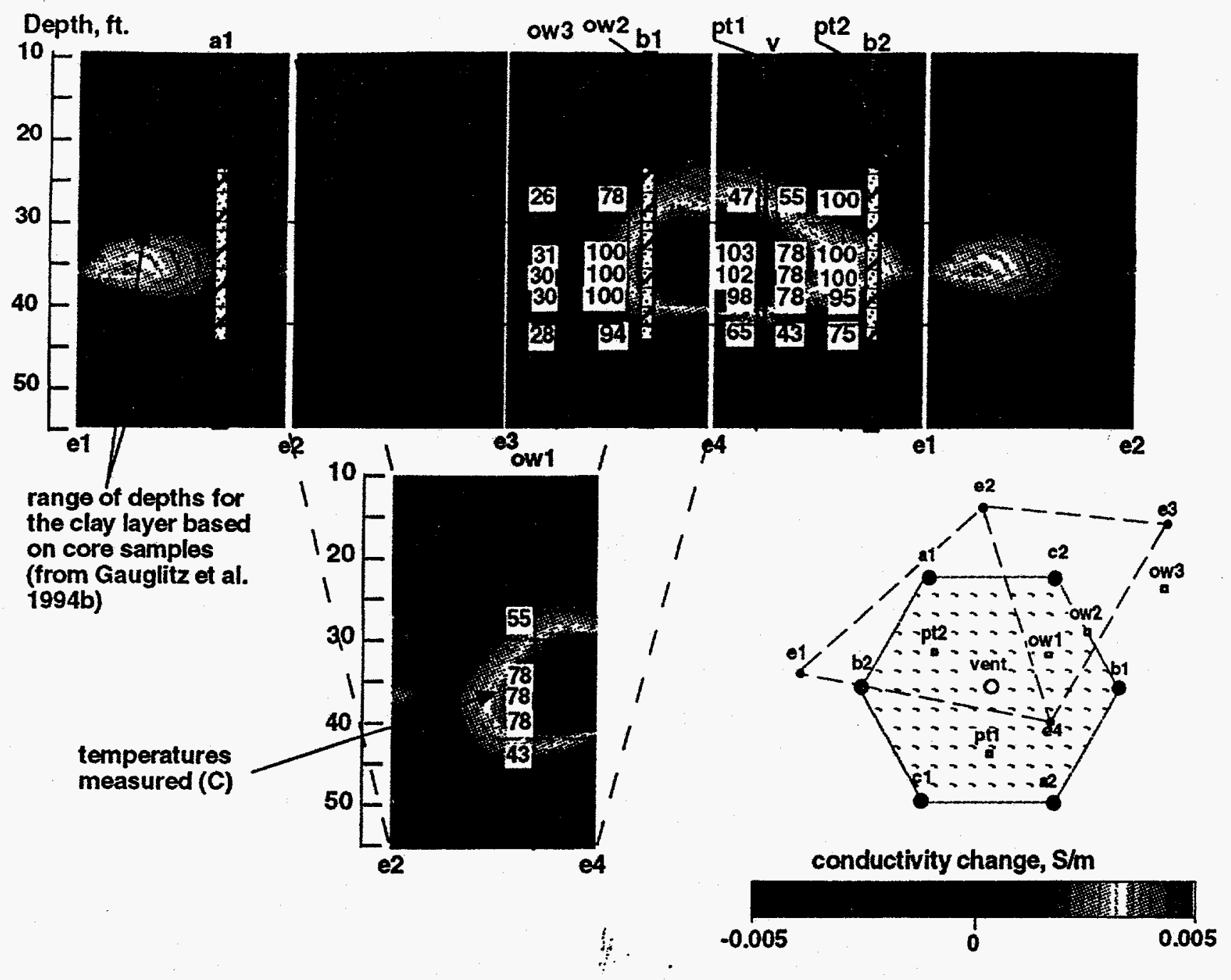

Figure 7. Conductivity difference images representing the changes in electrical conductivity observed after approximately two weeks of heating. These images were calculated by subtracting the 11/01/93 tomographs (collected a few days prior to the start of heating) from the $11 / 17 / 93$ tomographs. The locations of the ERT boreholes (e1, e2, e3, e4), heating electrodes and the extraction well were projected to the closest ERT plane. These projected locations are shown for reference. Also shown are temperatures (degrees $0 \mathrm{C}$ ) measured by Gauglitz et al (1994b) along various boreholes (ow2, ow2, pt1, and pt2). 


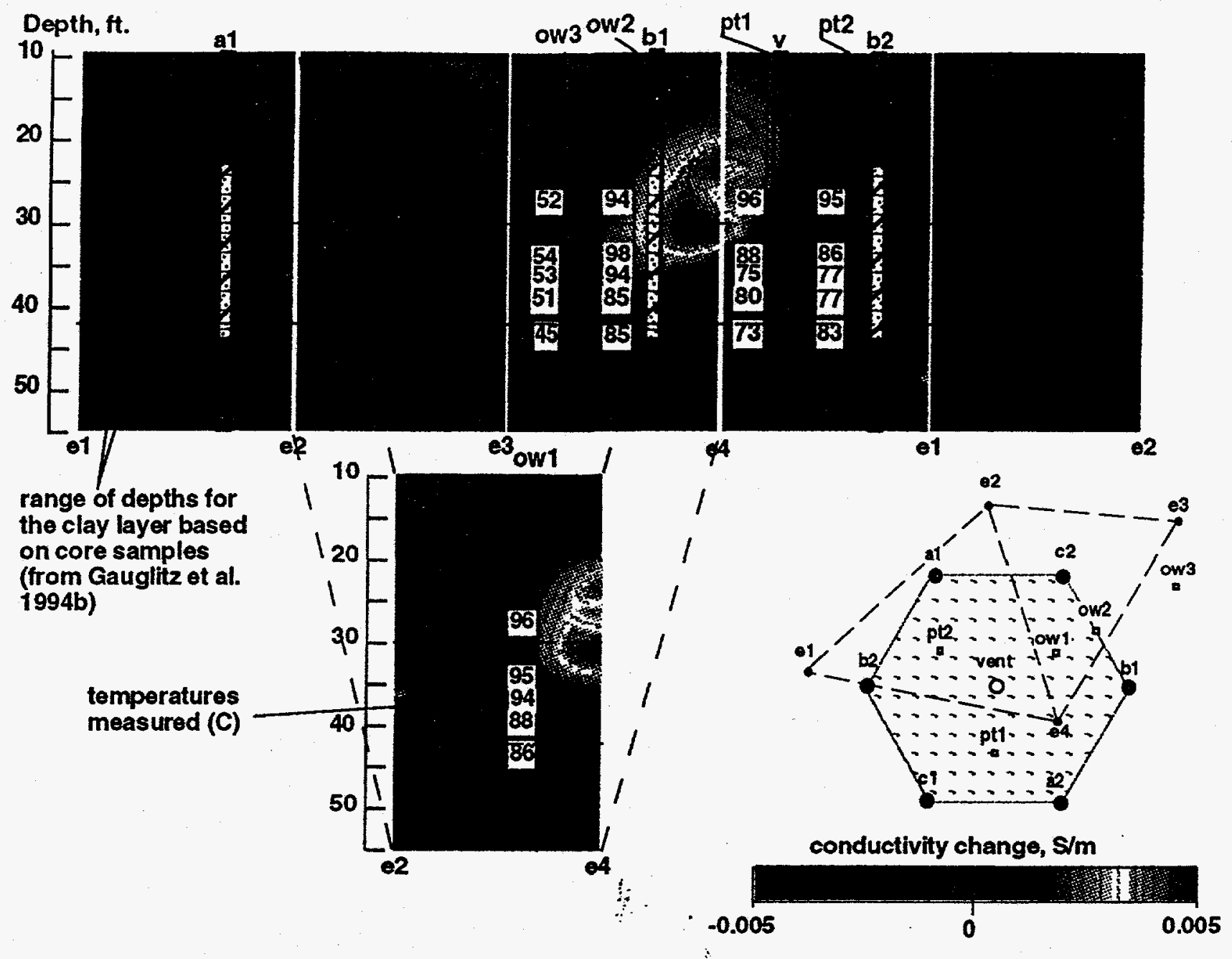

Figure 8. Conductivity difference images representing the changes in electrical conductivity observed near the end of the heating phase after approximately four weeks of heating. These images were calculated by subtracting the 11/01/93 tomographs (collected a few days prior to the start of heating) from the 12/01/93 tomographs. The locations of the ERT boreholes (e1, e2, e3, e4), heating electrodes and the extraction well were projected to the closest ERT plane. These projected locations are shown for reference. Also shown are temperatures (degrees C) measured by Gauglitz et al (1994b) along various boreholes (ow2, ow2, pt1, and pt2). 


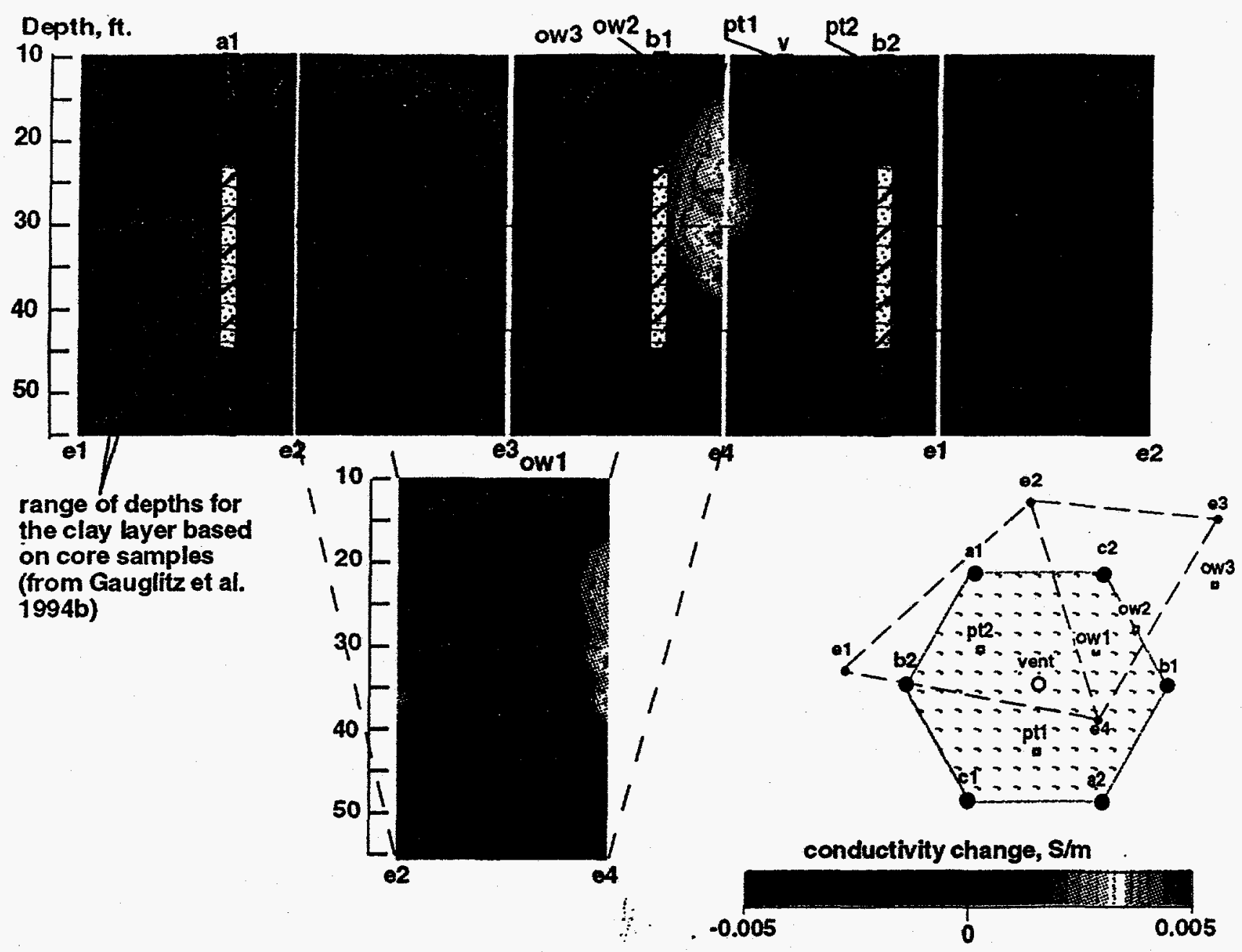

Figure 9. Conductivity difference images representing the changes in electrical conductivity observed approximately 12 days after the end of the heating phase during the period in which vacuum extraction continued. These images were calculated by subtracting the 11/01/93

tomographs (collected a few days prior to the start of heating) from the 12/14/93 tomographs. The locations of the ERT boreholes $(e 1, e 2, e 3, e 4)$, heating electrodes and the extraction well were projected to the closest ERT plane. These projected locations are shown for reference. 


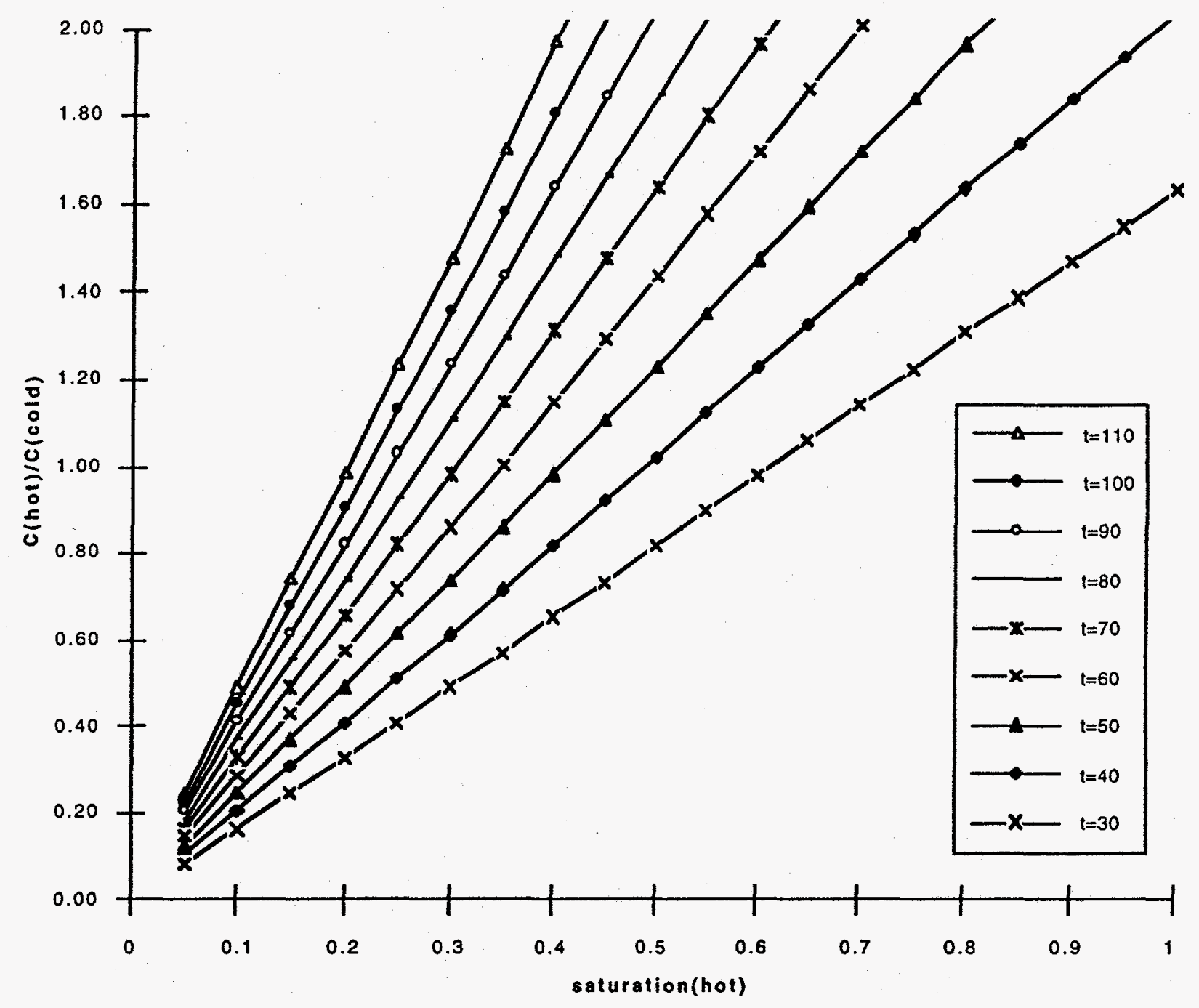

Figure 10 shows plots of saturation versus conductivity ratios (conductivity before heating $\left(C_{t 1}\right)$ / conductivity after heating $\left(\mathrm{C}_{\mathrm{t}_{2}}\right)$ ) as a function of saturation $\left(\mathrm{S}_{\mathrm{w} 2}\right)$ and temperature $\left(\mathrm{T}_{2}\right)$. 
